\title{
A InfluênCia do Modelo de Gestão de Polícia Comunitária na D emocratizaÇão da Polícia Militar do Espírito Santo, NA Cidade de Vitória, entre 1994 e 2006
}

Gelson Lozer Pimentel MestreAdministração pda UFES, Badhard em Administraçãopda UFES eCapitãoda PMES, atualmenteldtadona Dirtaria deEnsino da PMES, com subchefeda Divisão deEnsino da PMES glsonlozere@hatmil.com

Ricardo Roberto Behr Dautor emEngenhania deProdução pda UFSC, Pós Dattor emAdministração pda UFMG, Professor db Departamento deAdninistração edb Programa dePós GraduaçãoemAdministração(PPGAdm) da UniversidadeFedeal do Esánito Santo- UFES nicardbbdr@hatmail.com

\section{RESUMO}

A segurança pública é um tema amplamente debatido pela imprensa. Muitos países gastam enorme quantidade de tempo e dinheiro pensando numa maneira eficaz de reduzir a criminalidade. Este artigo tem como objetivo apresentar uma alternativa de gestão policial militar, denominada policiamento comunitário-interativo, que integre policiais e cidadãos, que vai de encontro ao modelo tradicional de policiamento, fruto de uma polícia guerreira, patrimonialista e sectária, características essas presentes desde a gênese das polícias. Para tanto, apresentam-se as diferenças de gestão entre a polícia comunitária-interativa e a polícia tradicional. Na metodologia, foram aplicadas entrevistas semiestruturadas em profundidade com praças, oficiais e lideranças comunitárias que vivenciaram as mudanças no modelo de policiamento ostensivo em Vitória, no período de 1994-2006. Conclui-se que a PMES foi interativa até o final do século XX; entretanto, depois disso, ela retrocedeu ao mo-delo de gestão tradicional.

Palavras-chave: Polícia Comunitária. Polícia Cidadã. Participação. Democratização da Polícia. Políticas públicas de Segurança.

\section{ABSTRACT}

Theinmesinglexd of videncehas madepublicsafeya widdy discussed issuein themedia, and has led countries to spend a huge amount of timeandmoney trying to find an effectiveway of reduing ciminality. This artideaims topresent a newaltemativeto military pdicemanagenent, whichjains pdiceofficersand atizens, called commuity podiang, which represents a major shift from the traditional modl of poliaingandits vamior, patrimonialist and setarian roots Thestudy idantifies and asseses themein differences between thetwomodis By condurtinga series of semi-structured, deepinterviens with offices, non-officers and community leadas that lived the hanges in theostensivepdiangmodd in Vitoria in the period of 1994-2006. It was conduded that the military pdice of theStatef Esánito Santo vas interadiveuntil theend of theXX century; howere, after that it has remogessed to thetraditional management approach

Keywords: CommuityPdiang PdiceCitizen Interadion Pdice Demoratization PuldicSafey Pdioy. 


\section{IINTRODUÇÃO}

0 presente trabalho tem como objetivo apresentar uma alternativa de gestão policial militar que integre policiais e cidadãos, denominada policiamento comunitário-interativo. Esta pesquisa delimita-se a uma análise das influências do contexto social que propiciaram a transformação de um modelo autocrático de gestão para um modelo democrático. Para tanto, apresenta as diferenças entre o policiamento tradicional e o outro, que procura uma interação e 0 atendimento dos anseios da comunidade.

Esta pesquisa procura analisar a percepção dos policiais e das lideranças comunitárias sobre polícia comunitária. Busca-se uma atenção especial à comunitarização dos assuntos de segurança pública, visto que a Polícia Comunitária envolve todos os órgãos públicos e privados que têm condições de influenciar a segurança pública de sua localidade.

Um dos autores deste trabalho, que atua como oficial da Polícia Militar e que não faz parte dos entrevistados desta pesquisa, vivenciou, ao longo de quinze anos de carreira, situações de angústia, e tinha como hábito conversar informalmente com superiores, pares, e principalmente com subordinados. Nessas conversas informais, constatou-se um discurso destoante de um policial para o outro, independentemente do posto ou da graduação. Não havia uma filosofia padronizada em toda a organização. Essa vivência pode ser caracterizada como observação simples, incorporada na análise.

Esses discursos destoantes podiam ser motivados pela tentativa de transformação da filosofia tradicional para uma polícia comunitária, aplicável a uma sociedade verdadeiramente democrática e participativa. Entretanto, a organização esbarrava nas concepções forjadas nos tempos do regime militar, cujo distanciamento entre 0 policial e 0 cidadão era incentivado pela organização pesquisada.

No Brasil, alguns pesquisadores têm discutido a questão da segurança pública, mais especificamente a polícia comunitária, entre eles Cruz; Barbosa. Em artigo publicado em 2002, procuram um caminho para solucionar o crescente problema da violência e da criminalidade no Brasil, e encontram no policiamento comunitário uma estratégia das polícias para reduzir os delitos e tranquilizar a população, pois a proximidade com o cidadão efetiva o controle ao crime.

Zouain đal (2005) também apresentam estudo sobre 0 policiamento comunitário como fator estratégico para a implantação de políticas públicas de segurança, sendo a participação dos gerentes como também dos executores primordial para os objetivos de mudança do policiamento tradicional para 0 modelo comunitário de policiamento, que tem suas atitudes legitimadas pela população local envolvida.

0 presente artigo traz como contribuição a possibilidade de um entendimento dos elementos constituintes das ações dos policiais militares em suas inter-relações sociais, de forma a enriquecer 0 debate junto à própria corporação sobre os modelos de gestão e lideranças comunitárias. Esse debate compreende a participação democrática no modelo de gestão da Policial Militar e os reflexos da forma de atuar junto à população.

\section{POLICIAMENTO TRADICIONAL VERSUS POLI- CIAMENTO COMUNITÁRIO}

"As polícias podem se adaptar às evoluções, virar as costas a seus valores e práticas tradicionais, abandonar suas rotinas, para inventar novas formas de intervenções e de respostas, adaptadas às novas necessidades?" (MONET, 2001, p. 288).

O regime político democrático, segundo Monet (2001), depende da qualidade da sua polícia e do apego dos policiais aos valores que o fundamentam. Portanto, a polícia desempenha um papel político decisivo, que não deveria se resumir a uma questão técnica. $\mathrm{O}$ autor é enfático ao afirmar que a democracia necessita da polícia:

Uma sociedade livre não pode dispensar um certo nível de ordem, ou ainda de previsibilidade, nas trocas sociais cotidianas. [...] Não só os cidadãos esperam da polícia que ela lhes assegure um certo nível de segurança, mas lhe pedem que o faça de tal modo que sua convicção democrática saia reforçada (MONET, 2001, p. 29).

Então, a instituição de regimes democráticos requer da polícia, como força pública, novas atribuições e posturas, de modo a fazê-la assumir um direcionamento progressista em que prevaleça o policiamento orientado para a comunidade. Segundo Bondaruk (2004, p. 56), "Polícia Comunitária é uma forma técnica e profissional de atuação perante a sociedade numa época em que a tecnologia, qualidade no serviço e 0 adequado preparo são exigidos em qualquer profissão".

Essa vinculação entre modelo de policiamento comunitário e democracia é crucial, segundo Goldstein (2003, p. 13), porque "para manter o grau de ordem que torna possível uma sociedade livre, a democracia depende de maneira decisiva da força policial".

$\mathrm{O}$ policiamento orientado para a comunidade ou policiamento comunitário parte do princípio central de que a sociedade deve exercer um papel ativo e coordenado na busca pela segurança, atuando como coprodutora da segurança e da ordem junto com a polícia. Nesse cenário, novas responsabilidades são impostas à polícia no que diz respeito à inclusão do público como ator social no campo do policiamento e da segurança pública. Além disso, é importante destacar que Polícia Comunitária, segundo Bondaruk (2004, pg. 48), "é um conceito mais amplo que abrange todas as atividades voltadas para a solução dos problemas que afetam a segurança de uma determinada comunidade, que devam ser praticadas por órgão governamentais ou não". A participação envolve grandes forças da sociedade: a polícia, a comunidade, autoridades civis eleitas, a comunidade de negócios, outras instituições e a mídia.

O modelo tradicional, designado por Beato; Marinho (2006, p. 31) como policiamento profissional, "prioriza as táticas de respostas rápidas às chamadas dos cidadãos, o patrulhamento em automóveis em detrimento do policiamento a pé, maneiras limitadas de contato com a comunidade que a legitima". Por essa lógica, o modelo profissional desconsidera a importância do ambiente institucional em que se insere. 
[...] métodos tradicionais usados para combater o crime incluem detenção (através de patrulha preventiva ou prisão), incapacitação e reabilitação. [...] as polícias têm adotado completamente (epromovido através dos anos) a imagem de combatente do crime [...]. Um dos maiores problemas com o policiamento tradicional tem sido a confiança excessiva no policiamento repressivo como principal instrumento de controle do crime e da desordem. Qualquer que seja o problema, a primeira inclinação dos policiais e fazer uma prisão, e esta tendência é resultado tanto da pressão da comunidade quanto da pressão de dentro da organização policial (ROSEMBAUM, 2002, p. 32-38).

Existe ainda uma dificuldade acentuada da organização policial militar de mensurar o trabalho preventivo do policial de rua, ou seja, de identificar todas as ocorrências que deixaram de acontecer devido à atuação proativa do policial. D estarte, os policiais também pensam que somente com prisões e apreensões terão feito seu papel policial. Se o policial não tiver feito qualquer prisão ou apreensão, ao chegar ao término da escala, ele acredita que seu turno de serviço foi improdutivo.

E notório que há uma diferença essencial entre o policiamento tradicional e 0 policiamento comunitário. 0 primeiro é direcionado para a advertência, a ameaça, a força e a agressão, enquanto o segundo enfatiza a solicitação, 0 auxílio, o convite e o encorajamento, tendo como objetivo basilar a prevenção do crime com a comunidade. Outra situação que caracteriza o policiamento comunitário é a sua capacidade de interagir de forma respeitosa com a diversidade do público, buscando sempre a legalidade de seus atos.

Essa concepção de modelo de trabalho policial remonta, no entendimento de Skolnick; Bayley (2002), ao trabalho pioneiro de Arthur Woods, Comissário de Polícia da Cidade de Nova Iorque, entre os anos 1914 a 1919, período em que ele destacou a importância social, a dignidade e o valor público da atividade policial em uma série de palestras desenvolvidas com as camadas subalternas da hierarquia do policiamento. D efendia de forma convincente a tese de que se 0 público fosse esclarecido a respeito da função policial a polícia seria mais respeitada e receberia recompensas pelo desempenho consciente e eficaz.

A implantação da Polícia Metropolitana de Londres, em setembro de 1829, também teve sua contribuição na formulação dos princípios do policiamento comunitário. Ao rejeitar o modelo de polícia militar francês, que primava pela proteção da estrutura do Estado e a manutenção da ordem social interna, a opinião pública britânica forçou as autoridades a elaborarem um projeto de polícia pioneiro: polícias bem ostensivas, fáceis de ser controladas pela população, transpassando a visão de uma polícia secreta, cujo uniforme e equipamento não representam uma força militar ditatorial. O modelo britânico adentrou o Continente Europeu levando ainda a concepção preventiva e não somente a reativa, de maneira que a polícia não permanece estanque, aguardando tão-somente o crime ocorrer para entrar em cena, mas, acima de tudo, inibe comportamentos criminosos.
No policiamento comunitário, o patrulhamento a pé ganha um enfoque privilegiado em relação ao motorizado, considerando que essa última modalidade é vista como uma caixa em movimento na cidade, e aquela é marcada realmente pela presença policial na rua (MONJARDET, 2003). A despeito das vantagens do patrulhamento motorizado, como atendimento rápido às chamadas e um grande alcance territorial, o policiamento a pé tem melhores condições de observação e possibilita um contato mais próximo à população, podendo estabelecer relações de confiança e obtenção de fontes de informação (MARINHO, 2002). Além disso, um estudo de Wilson; Kelling (apud MARINHO, 2002) demonstrou que os moradores dos bairros nos quais o policiamento a pé foi implantado tinham uma sensação de segurança maior do que as pessoas residentes em localidades onde essa modalidade não havia sido implementada. Naqueles bairros, as pessoas tendiam a acreditar que a criminalidade havia sido reduzida.

\section{DEMOCRACIA E PARTICIPAÇÃO NA GESTÃO DA POLÍCIA MILITAR DO ESPÍRITO SANTO}

No entendimento de Goldstein (2003), nas Polícias Militares existem linguagem e padrões de comportamento ímpares, diferentes de outras organizações. Muitas atitudes são tipicamente de policiais militares, rapidamente identificados em um contexto social. Entretanto, o policial militar já se depara com uma contradição na gênese de sua formação, considerando que militar é diferente de policial: militar é força expandida e policial é força comedida. 0 treinamento de um policial segue a corrente da compreensão e do diálogo; já o treinamento de um militar está voltado para as ideologias positivistas fundamentadas na execução sem questionamentos das ordens emanadas de seus superiores. No entanto, muitas vezes o policial não aceita aquele tipo de formação autoritária: "a gente tem aquele treinamento do robô, do homem automatizado, e muitas vezes o homem faz aquilo, mas não está aceitando. Faz porque é obrigado a fazer" (CERQUEIRA, 2001, p. 28).

Alguns estudiosos tratam as organizações como se fossem um segundo marcador social, enquanto a família, os amigos, a rede de relações pessoais atuariam na construção da identidade das pessoas. Entretanto, essa afirmativa não corresponde à identidade de um policial militar, que se confunde com a própria organização a que pertence. 0 cidadão que antes de ingressar na corporação era conhecido como fulano, beltrano ou cicrano, posteriormente passa a ser reconhecido, intra e extracorporação, como soldado fulano, cabo beltrano ou sargento cicrano. Segundo Monjardet (2003), a população vê os policiais como seres individualizados e identificados. Para a sociedade, o policial é conhecido com e sem seu uniforme de trabalho.

Aonde quer que o policial vá, ele é sempre um policial militar e tem toda uma peculiaridade de agir e de ser tratado pela sociedade em que está inserido. Essas conclusões são facilmente comprovadas pela Lei 3.196 (1996), que regula a situação, as obrigações e os deveres, os direitos e as prerrogativas dos policiais militares. Tal legislação trata, por exemplo, 
do respeito do policial à dignidade da pessoa humana e do proceder de maneira ilibada em sua vida pública e particular, zelando pelo bom nome da Polícia Militar e de cada um dos seus integrantes, obedecendo e fazendo obedecer aos preceitos da ética policial-militar.

A citação dessa lei policial militar é importante para que se compreenda um pouco da subjetividade do policial militar, tendo em vista que os ensinamentos supracitados continuam sendo ministrados para os cursos de formação da PME S pela disciplina Legislação Policial Militar.

Para uma cultura organizacional ser modificada e aceita, é importante a participação de todos os seus integrantes. Segundo Motta (1984, p. 11), "a preocupação com a participação surge com a crescente impossibilidade de administrar 0 conflito apenas através da coação física”. Se uma mudança cultural é tentada somente com a participação dos altos níveis hierárquicos, haverá pouca legitimidade pelos escalões subalternos. Então, é importante envolver todos os níveis organizacionais militares, por meio das mais variadas metodologias, entre elas cursos, seminários, dinâmicas, pois uma nova forma de agir deverá ser bastante forte e consistente para se sobrepor à anterior e ainda deverá ser bastante sólida para não permitir o retorno àquela. D o contrário, será uma pseudoparticipação, como descrito por Pateman (1992, p. 95), ou seja, somente "técnicas utilizadas para persuadir os empregados a aceitarem decisões já tomadas pela administração".

$G$ rande parte das vezes podem ocorrer a corrupção e 0 mau uso dos recursos públicos quando os gestores das organizações públicas não são fiscalizados e controlados pela comunidade, pela participação efetiva dos moradores,. O utro aspecto importante é que o indivíduo como um ser social gosta de opinar, exprimir suas ideias e saber que seu pensamento serve no desenvolvimento de algum projeto. Segundo Bordenave (1998), a participação é inerente à natureza social do homem, tendo evoluído desde a tribo e o clã dos primórdios da existência da sociedade chegando à contemporaneidade das associações, empresas e dos partidos políticos contemporâneos.

Um fator importante relativo à participação é considerar que a criatividade dos indivíduos da organização não se restringe aos níveis de gerência. Para que ocorra uma ação democrática é preciso aumentar a capacidade de expressão e de criatividade das pessoas que são ou serão envolvidas numa tomada de decisão. Quando se motiva a participação de todos os empregados da organização, permite-se que as ideias maximizem a qualidade dos serviços prestados pela empresa. Assim, "cada organização deve dar oportunidade para que seus membros usem sua criatividade no desenvolvimento da empresa" (BO RD ENAVE, 1998, p. 43). Nota-se então que 0 policiamento comunitário está diretamente ligado ao conceito de participação, o que é corroborado por de Zouain $\notin$ al. (2005, p. 2), quando afirmam que "o que se caracteriza como objetivo desta política é promover a participação, tanto dos responsáveis pela execução quanto daqueles que impõem, de certo modo, os objetivos a serem alcançados".

\section{METODOLOGIA}

Esta pesquisa é de caráter qualitativo que, segundo Minayo (1994, p. 21-22), é aquela que:

\begin{abstract}
responde a questões muito particulares. Ela se preocupa, nas ciências sociais, com um nível de realidade que não pode ser quantificado. $\mathrm{Ou}$ seja, ela trabalha com 0 universo de significados, motivos, aspirações, crenças, valores e atitudes, o que corresponde a um espaço mais profundo das relações, dos processos e dos fenômenos que não podem ser reduzidos à operacionalização de variáveis.
\end{abstract}

D essa forma, foram realizadas entrevistas semiestruturadas e em profundidade com sujeitos de pesquisa escolhidos intencionalmente. Todas as entrevistas foram gravadas e transcritas, levando cada uma o tempo de aproximadamente uma hora. Portanto, foi uma amostra não probabilística que, segundo Gil (1999, p. 101), é aquela que "não apresenta fundamentação matemática ou estatística, dependendo unicamente de critérios do pesquisador". D ecidiu-se então por uma amostra por acessibilidade, pois os entrevistados foram os sujeitos que estavam disponíveis e que vivenciaram tanto 0 policiamento tradicional quanto o policiamento comunitário. O grupo de entrevistados era composto por policiais lotados nas cinco Companhias subordinadas ao $1^{\underline{0}}$ Batalhão de Polícia de Vitória, sendo cinco praças (soldado a subtenente), cinco oficiais (tenente a coronéis) e cinco lideranças comunitárias, além de atores civis envolvidos no processo residentes na área de abrangência dessa unidade militar.

As entrevistas com as lideranças comunitárias foram necessárias para se compor um referencial mais profundo de análise do processo de construção subjetiva, visto que, na quase totalidade das situações, essas lideranças são um bom referencial da visão da comunidade por elas liderada. 0 objetivo também foi traçar um paralelo entre o pensamento do público interno e externo á PMES.

Buscou-se entrevistar policiais que sabidamente tinham um conhecimento mais aprofundado sobre a filosofia de Polícia Comunitária, porjá terem trabalhado diretamente com ela, bem como policiais que, em princípio, não tinham conhecimento de sua participação ativa sob tal filosofia. Também houve um empenho em entrevistar policiais que trabalhavam em diferentes companhias do $1^{\circ} \mathrm{BPM}$. Tal metodologia foi necessária para construir uma análise que pudesse fomentar as divergências que, porventura, ocorressem. Caso fossem entrevistados somente policiais vinculadas à filosofia de Polícia Comunitária e de uma mesma localidade, provavelmente não ocorreriam essas divergências.

Procurou-se entrevistar também as lideranças comunitárias provenientes das mais diversas localidades da cidade de Vitória, mas, diferentemente dos policiais militares, não havia liderança que não tivesse atuado diretamente com a filosofia de Polícia Comunitária. Isso porque tal filosofia orientou as ações do comando do 1ํㅡ BPM, ou seja, todos os comandantes de companhia, que tinham sob sua circunscrição vários bairros, deveriam cumprir a determinação de re- 
alizar reuniões periódicas com as lideranças comunitárias de sua região e de fomentar a participação comunitária, para, com base nas necessidades do grupo, tentar equacionar 0 emprego do seu efetivo policial militar.

A forma de análise dos dados foi a de conteúdo conforme descrito por Minayo (1994), em que se procurou descobrir o que estava por trás dos conteúdos manifestos, além das aparências do que estava sendo comunicado, a fim de se complementar as respostas para a questão de pesquisa, buscadas durante a apreensão de dados.

O corte temporal da pesquisa se deu entre 1994 a 2006. Esse intervalo de tempo foi escolhido levando-se em consideração que a Polícia Comunitária no Estado do Espírito Santo teve seu início no ano de 1994.

\section{APRESE NTAÇÃO E ANÁLISE DOS DADOS}

\subsection{Policiamento Tradicional}

D o depoimento dos entrevistados pode-se extrair inúmeros trechos que retratam o policiamento tradicional. Trata-se de testemunhos importantes para a percepção, na prática, do que realmente descrevemos como policiamento tradicional.

Eu nem sabia qual era a sala do comandante, eu nem sabia onde ficava a porta do comandante da companhia. Para eu chegar e tentar reivindicar alguma coisa eu tinha que falar com o sargenteante1. Ele perguntava o que eu queria conversar com o comandante. Ele dizia: você não está autorizado (...). Ele era 0 meu juiz. Se ele sentisse que eu fosse reclamar da escala que fosse de encontro à pessoa dele, eu não poderia ir de forma nenhuma e se fosse era comunicado 2 . Naquela época não tinha o RD ME 3 , legítima defesa, a gente era punido mesmo (Praça 02).

No trecho acima, é perceptível o grau de autoritarismo e a ausência de participação popular, o que traz prejuízo para a otimização do emprego policial e a falta de motivação do policial.

Num contexto geral acabaram com as companhias e 0 que aconteceu? A área ficou muito extensa e, infelizmente, não deu conta. A administração saiu daquela região; ou bem ou mal ainda funcionava e, infelizmente, cortou o vínculo com a comunidade. Precisam ouvir mais a base, ouvir quem trabalha na viatura, ouvir o PO 4, ouvir o comandante de companhia porque na verdade é ele que lida com a comunidade (O ficial 03).

0 relato anterior retrata o que aconteceu no batalhão que policia a capital do Espírito Santo. Esse episódio não diverge muito da forma de atuação gerencial do regime militar, época em que não havia qualquer tipo de participação tanto interna quanto externa em assuntos de interesse social como a segurança pública.

0 policiamento no início da década de 90 era mais de choque em cima dos traficantes. Isso quando era chamada; se não fosse chamada dificilmente a polícia vinha. Era muito difícil, o estilo daquela época era diferente. Era somente de reação, se houvesse algum problema aqui ela vinha. Mas não havia policiamento preventivo e patrulhamento sendo feito (Liderança comunitária 01).

Essa é a visão do modelo reativo de esperar o crime ocorrer para depois intervir, mas as "cicatrizes" deixadas nas vítimas são difíceis de ser fechadas, e, por mais que se capture e prenda um homicida, não há como ressuscitar a sua vítima.

Eu presenciei alguns casos, de ver o bandido algemado tomando chute e tomando tapa. É aquele negócio, a gente age às vezes com o coração. Ao mesmo tempo em que a sociedade quer que a polícia seja cidadã, seja cortês; ela pede que os caras ajam, depende da situação (Liderança Comunitária 02).

Eu moro hoje próximo de um morro, o cidadão de bem fala: o policial chegou, bateu, escancarou; não precisava disso; ele podia chegar numa boa, a gente sabe quem é ruim e quem é bom, a gente até se aproximava mais, mas não, ele chega dando tapa, ele chega batendo. Uns eles até elogiam, a minoria; a maioria chega batendo, chega truncando. Eles próprios dizem: se eles fossem mais cautelosos até o pessoal da comunidade confiava em dar as informações (Liderança Comunitária 02).

Nos dois relatos anteriores, apesar de o policial militar ser fruto da sociedade e essa, por vezes, pensar que o policial no "calor" da prisão deva ser o juiz do detento, os profissionais de segurança pública devem fazer cumprir a Lei e preservar a integridade física do suposto criminoso. 0 policial militar só tem a ganhar agindo dentro da legalidade, tanto salvaguardando sua carreira como angariando a simpatia de muitos colaboradores.

Eles até alegavam: quando chegar para trabalhar com 0 povo não tem esse negócio de vir conversando manso não, tem que chegar e se impor, é chegar com voz firme, é mostrar que você que manda, paisano é paisano, é como se fosse um bicho e o policial é que mandava porque naquela época não tinha um respeito, mas tinha um temor da população, o pessoal respeitava, ficava com um pé atrás em relação à polícia, quando a polícia chegava o cara parava tudo o que tava fazendo e acabou, ou por bem ou por mal tinha que parar, se tava jogando, se tava no bar..., não interessava, uma guarnição chegava, era como se fosse assim na época do velho oeste, o cara chegou todo mundo recua e fica to do mundo mansinho, a população na verdade temia a polícia (Oficial 03).

Nós sabíamos que se nós não adotássemos posturas bem rígidas, esses profissionais poderiam se exceder e levar você inclusive a também cometer excessos ( 0 ficial 01).

Esses últimos dois trechos de entrevistas foram mencionados com o objetivo de apresentar bons exemplos de policiamento tradicional, com ensinamentos e práticas autoritárias, pois o aplicador entende como mais fácil e rápido se impor pela coerção. Porém, o respeito e a confiança se adquirem somente com muita participação e respeito aos direitos e à dignidade de todos os cidadãos.

Mesmo com a adoção do modelo comunitário, é necessário ter em mente que a polícia mantém como objetivo precípuo a redução do crime; entretanto, são feitos reordena- 
mentos almejando-se conquistar o citado modelo por meio de estratégias indiretas, envolvendo funções policiais diversas. Para Rosenbaum (2002), um fator marcante no modelo de policiamento comunitário é o foco na prevenção de "problemas". Nele, o policial imagina que sua atuação esteja encerrada quando atende à reclamação do cidadão sobre um incidente específico.

Em matéria publicada pelo jornal Folha de São Paulo, D imenstein (2006) trata da redução da criminalidade, em especial dos homicídios, em duas das cidades mais violentas do mundo: Bogotá e Medellín. Na reportagem intitulada "A capital mundial da violência", 0 autor destaca que grande parte da drástica redução da taxa de homicídios deveu-se à "comunitarização" das práticas de gestão de segurança pública, com a participação de diversos segmentos da sociedade, principalmente dos grupos marginalizados da sociedade, como ex-membros das FARC5 e paramilitares. Essas lideranças eram convidadas a participar de programas sociais visando resgatar pessoas em risco potencial de se envolverem em situações conflituosas com a sociedade.

\subsection{Policiamento Tradicional e Policiamento Comuni- tário}

No quadro $n^{0}$ 1, elaborado por Bondaruk (2004), estão demonstradas as diferenças entre a polícia tradicional e a polícia comunitária, o que auxilia no entendimento sobre as peculiaridades de cada gestão. conselhos interativos eu acho que a polícia mudou da água para o vinho. Realmente tornou-se uma polícia cidadã. Hoje, do jeito que o senhor conversa com um policial soldado, o senhor conversa com um oficial lá no batalhão, são pessoas hoje que são policiais de escola (Liderança Comunitária 01).

Um caso que é muito sintomático e é importante que se diga e que nos chamou muita atenção, pelo menos para mim, é que enquanto a polícia militar era vista sempre um pouco de lado, assim como eu disse, tendo ainda aquele ranço da dita revolução, do regime de exceção, ela mudou completamente e se integrou. A Polícia Civil, por outro lado, apesar de ter o nome civil, a comunidade civil não conseguiu ter esta ligação, pois as movimentações de delegados e outros membros da civil é uma constante. Você acaba não criando laços de amizade, laços de confiança, de empatia de o policial conhecer a comunidade, conhecer melhor, se integrar mais à comunidade. A polícia militar transformou completamente o seu efetivo, que agora ao incutir naquele policial que ele é um cidadão fardado, que deve satisfações à comunidade, então começaram a preparar os oficiais, os praças, os intermediários, sargentos, para esse contato mais cortês com a comunidade. Eu acho que houve uma mudança muito grande, de que a polícia não é vista mais como a repressora, aquela que só chega batendo, a polícia já é vista como uma parceira da comunidade (Liderança Comunitária 03).

A própria formação policial já mudou e muito. E da década de 90 para cá com a criação da Polícia Interativa, com a parte de Direitos Humanos e as técnicas de

\begin{tabular}{|l|l|}
\hline Policiamento tradicional & Policiamento comunitánio \\
\hline Policial trabalha em vários bairros; & Policial trabalha sempre no mesmo bairro; \\
\hline Policial é anônimo; & Policial é conhecido da comunidade; \\
\hline Baixo grau de participação da comunidade; & Alto grau de participação da comunidade; \\
\hline A polícia é reativa; & A polícia é proativa; \\
\hline Policial é mero executor; & Policial é chefe de polícia local; \\
\hline A iniciativa das ações é centralizada; & A iniciativa das ações é descentralizada; \\
\hline Enfase às unidades especializadas; & Enfase às unidades de área; \\
\hline Menor nível de motivação para o policial; & Maior nível de motivação para o policial; \\
\hline Autoridade imposta; & Cooperação e pensamento criativo; \\
\hline Informaçôes de alcaguetes; & Informações de cidadãos engajados; \\
\hline Policiamento pela intimidação; & Estabelecimento de laços de confiança; \\
\hline Chegada após a ocorrência; & Solução dos problemas por integração ativa; \\
\hline Trabalha a quantidade e generalização dos números; & Qualidade e resultados direcionados; \\
\hline A polícia elabora e indica as necessidades; & Comunidade indica suas necessidades; \\
\hline Carência quanto à redução do crime. & Redução do medo do crime. \\
\hline
\end{tabular}

Quadro 1: Comparativo policiamento tradicional e policiamento comunitário

Fonte: Bondaruk (2004, p. 54).

A transformação de uma polícia tradicional em uma polícia comunitária no ES se deu de acordo com as características evidenciadas no modelo de Bondaruk (2004), como fica claro nas entrevistas abaixo:

D e primeiro era muito difícil nós cidadãos comuns termos acesso ao comandante ou oficial da Polícia Militar. A gente ia lá e ele nunca estava ou não podia receber, mas depois que houve essa criação dos emprego da Polícia Interativa, também trouxe muita mudança para a atividade policial e 0 reconhecimento por parte da comunidade (Praça 05).

Porque antes o policial era pego a laço. Hoje para entrar a disputa está muito grande, então hoje o policial já está mais doutrinado, se exige o ensino médio para entrar na polícia. Então melhorou bastante desde o momento que eles colocaram os professores universitários para dar aula dentro do CFA, porque antigamente os oficiais eram 
os instrutores, formados em várias academias, era 0 militarismo mesmo, o coronelismo e acabou (O ficial 03).

0 cara que não aceita mudança é um idiota porque mudança vai existir sempre (O ficial 04).

Nos trechos das entrevistas anteriores ficam evidentes as diferenças entre as duas filosofias de gestão. Em particular, na última transcrição, o oficial da PMES usou uma frase forte para destacar que os tempos são outros e a mudança da forma de atuar da PMES é inevitável.

Corroborando o teor dessas entrevistas, há um estudo de Rolim (2006) que destaca que em todos os países do mundo está em curso uma importante mudança doutrinária nas polícias. A ideia de policiamento comunitário está se transformando no discurso oficial de muitas localidades, como, por exemplo, nos Estados Unidos, que atualmente têm na reforma policial parte integrante dos objetivos governamentais, aparentando ser um consenso entre os tomadores de decisão.

Abaixo se destacam trechos de entrevistas voltadas para a participação na gestão da PME S, com todos os entrevistados percebendo como de vital importância a interatividade entre os dois segmentos e dentro da própria Polícia Militar. Há uma incompatibilidade entre a existência de uma cultura ditatorial interna e a necessidade de um policial participativo e democrático com 0 cidadão.

A sociedade estava tão afetada com o processo, que ela queria da forma mais rápida possível avançar num processo de interagir com a Polícia Militar (Liderança Comunitária 02).

Sempre achei válido e é interessante para a Polícia Militar a parceria para fins de participação, trazer os problemas da comunidade, apontar os erros, criar os conselhos, mas de uma forma legal que atue junto com a Polícia Militar e junto com a comunidade, que seja um elo (Praça 02).

Penso como cidadão e como profissional; tenho certeza de que a comunidade e a sociedade querem uma aproximação com a Polícia Militar (Praça 03).

A comunidade sabe seus problemas e leva ao conhecimento da polícia. E a polícia, que é o órgão técnico, vai empregar os seus meios conforme a necessidade. A polícia comunitária se chegar a funcionar desse jeito vai ser maravilhosa (O ficial 02).

Para que ocorra uma ação democrática é preciso aumentar a capacidade de expressão e de criatividade das pessoas que são ou serão envolvidas numa tomada de decisão. Essa ideia é particularmente importante ao se considerar uma organização militar, historicamente conhecida pela ausência de participação dos militares que se encontram na base da instituição.

\section{CONCLUSÃO}

A Polícia Militar do Espírito Santo foi pressionada pelo ambiente e internamente pelos seus membros a implementar uma mudança em sua cultura organizacional. A organização era percebida pela sociedade como distante, agressiva, truculen- ta e com pouca qualificação profissional. Os profissionais valorizavam a força física em detrimento da capacidade criativa e intelectual. As ordens emanadas de um superior jamais poderiam ser questionadas, e havia um abismo entre superior e subordinados bem como entre o cidadão comum e o policial militar.

Com a queda do regime militar e com a ênfase conferida aos Direitos Humanos, no final da década de 90, foi criado um setor para apurar os "desvios de conduta" dos policiais militares, a Corregedoria da PMES, dando origem a uma série de canais como o disque-denúncia e a ouvidoria de polícia, por meio dos quais o cidadão pode se queixar de supostos abusos cometidos por policiais.

Entretanto, mesmo com o início dos governos democráticos, ainda se manteve enraizada na cultura policial militar a postura de combater e reprimir, muitas vezes com a utilização de técnicas cruéis e degradantes contra o suposto inimigo do regime militar. A tentativa de modificar a forma de atuação da PME S teve grande resistência entre seu público interno, que percebia essa tentativa como uma maneira de reduzir sua autoridade e seu poder de polícia, e até mesmo alguns oficiais pensavam que deveriam se curvar ante os desejos do "paisano". E ssa resistência ainda perdura no imaginário de alguns desses policiais nos dias atuais.

Neste trabalho foi apresentada uma alternativa de gestão policial militar que integra policiais e cidadãos, denominada policiamento comunitário-interativo.

Por meio das entrevistas junto às lideranças comunitárias e aos policiais militares, constata-se que a polícia comunitária realmente influenciou a forma do emprego da força policial militar. Alguns entrevistados ratificaram que a polícia mudou sua forma de atuar, integrando-se com a sociedade.

Mesmo para aqueles que ainda relutam em aceitar a democracia e a participação social, colheram-se impressões impactantes, como a afirmação de que a pessoa que não aceita a mudança é um "idiota", enfatizando que mudanças sempre existirão e, nesse caso, a transformação da polícia tradicional para a comunitária-interativa foi para melhor.

Caso a Polícia Militar opte pelo policiamento comunitário, ele deve ser defendido de forma institucional. 0 Policiamento Comunitário deverá ser implantado de forma ampla, geral e irrestrita, com uma discussão que defenda, por exemplo, que até mesmo o Batalhão de Missões Especiais - cuja finalidade precípua é agir repressivamente nos distúrbios civis, sequestros, roubo com refém, rebeliões em presídios deve atuar com base nos preceitos comunitários. Uma nova filosofia institucional deverá ser definida, primeiramente, em seu nível estratégico, por se tratar de uma organização alicerçada na hierarquia e disciplina. Se os níveis hierárquicos mais elevados não entenderem quão importante é essa concepção, é praticamente impossível mudar uma filosofia enraizada na corporação há tanto tempo. Isso explicaria 0 porquê do retorno ao policiamento tradicional na PME S, pois, apesar de muitos entrevistados afirmarem que a polícia está muito cidadã hoje em dia, por outro lado todo o processo comunitário-interativo retrocedeu. 
Entretanto, de acordo com a pesquisa, o retorno da polícia comunitária é plenamente possível e todos os entrevistados anseiam por isso. Os benefícios para a sociedade decorrentes da polícia comunitária devem se sobrepor aos interesses pessoais e políticos, que atuam de forma ainda majoritária em nossa sociedade democrática.

\section{REFERÊNCIAS}

BEATO, Cláudio Chaves; MARINHO, Karina Rabelo Leite. Estratégja arganizacional depdiciamento comnitánionas adades deBdo Hanzante, Rio deJaneroeVitóna SENASP, 2006.

BO NDARUK, Roberson Luiz; SO UZA, César Alberto. Pdída Comunitária: polícia cidadã para um povo cidadão. Curitiba: Comunicare, 2004.

BORDENAVE, Juan Diaz. O que é partiaipaçãa 8 ed. São Paulo: Brasiliense, 1998.

CERQUEIRA, Carlos Magno Nazareth. Ofuturodeumailusãa o sonho de uma nova polícia. Coleção Polícia Amanhã. Rio de Janeiro: F. Bastos, 2001.

CRUZ, Marcus Vinicius Gonçalves; BARBOSA, Allan Claudius Queiroz. Modelos de policiamento para a gestão de segurança pública. In:XXVI ENCO NTRO NACIO NAL D OS PRO GRAMAS DE PÓS-GRADUAÇÃO EM AD MINISTRAÇÃO, 26, 2002, Brasília. Anais.. Brasília: ANPAD, 2002, p. 1-11.

DIMENSTEIN, Gilberto. Colômbia dá exemplo para Brasil reduzir a violência. Fodha deSão Paula São Paulo. 15.out.2006. p. C5.

ES. Lei 3.196, de 14 de janeiro de 1978. Regula a situação as dbrigaçoes e os deveres diritos e premogativas dos pdídias-militares. Leis da Polícia Militar. Vitória, agosto de 1996.

G IL, Antonio Carlos. Méodoseténicasdepesquisasocial. 5 ed. São Paulo: Atlas, 1999.

G O LD STEIN, Herman. Pdidando uma sociedade livre São Paulo: Editora da Universidade de São Paulo, 2003.

MARINHO, Karina Rabelo Leite. Mudanças arganizadionais na implementação do polidiamento commitánio. Belo Horizonte, 2002. Dissertação (Mestrado em Sociologia) FAFICH, UFMG.

MINAYO, Maria Cecília de Souza (O rg.). Pesquisa Sodal: teoria, método e criatividade. 7 ed., Petrópolis, RJ: Vozes, 1994

MO NET, Jean-Claude. Pdídas e sociedades na Europa: sociologia da Força Pública. São Paulo: Edusp, 2001.

MO NJARDET, D ominique. O que faz a pdíaia: sociologia da força pública. São Paulo: Edusp, 2003.

MOTTA, Fernando Carlos Prestes. Partiapação e CoGestãa Novas formas de administração. 2ª ed., São Paulo: Brasiliense, 1984.

PATEMAN, Carole. Partiạpaçãoeterna damorática Rio de Janeiro: Paz e Terra, 1992.

ROLIM, Marcos. A Síndrome da Rainha Vemdha: policiamento e segurança pública no século XXI. Rio de Janeiro: Jorge Zahar Ed; Oxford, Inglaterra: University of Oxford, Centre for Brazilian Studies, 2006.

RO SENBAUM, D. P. A. Mudança no papel da Polícia: Avaliando a transição para policiamento comunitário. In: BRO DEUR, Jean-Paul (O rg.). Como reconheeer umbom policiamenta problemas e temas. São Paulo: Edusp, 2002.

SKO LNICK, Jerome H.; BAY LEY, D avid H. Pdidamentocommitána questões e práticas através do mundo. São Paulo: Editora da Universidade de São Paulo, 2002.
WILSO N, James Q., KELLING, G eorge L. Broken Windons the police and neighborhood safety. In: Community policing - classical readings - Willard M. Oliver, prentice hall, 2000.

ZO UAIN, D eborah Moraes; RICCIO, Vicente; ZAMITH, José Luis Cardoso. Policiamento Comunitário: fator estratégico para implantação de política pública de segurança. In: XXIX ENCONTRO NACIONAL DOS PROGRAMAS DE PÓSG RAD UAÇÃO EM AD MINISTRAÇÃO , 29, 2005, Brasília. Anais.. Brasília: ANPAD, 2005, p. 1-10.

\section{NOTAS DE FIM DE TEXTO:}

${ }^{1}$ Sargenteante: Sargento que tem a função de confeccionar a escala de serviço de todos os policiais da companhia, além de sugerir elogios, confeccionar o plano de férias do efetivo, enfim todas as funções administrativas que envolvessem os componentes da companhia;

${ }^{2}$ Comunicado: termo utilizado para a confecção de um documento de um superior contra uma possível transgressão disciplinar do subordinado, sendo que se comprovada a culpa do subordinado, a pena poderia chegar até a reclusão, leitura pública da transgressão e qual a pena foi aplicada e ainda seria lançada nos assentamentos funcionais do policial;

${ }^{3} \mathrm{RD}$ ME : regulamento disciplinar do militar estadual, totalmente reformulado e voltado para a ampla defesa e o contraditório do policial militar;

${ }^{4}$ PO : Policiamento ostensivo, atividade fim da Polícia Militar, policiais que diuturnamente fazem o policiamento ostensivo a pé.

${ }^{5}$ FARC: Forças Armadas Revolucionárias da Colômbia.

Data de Submissão: 16/ 11/ 2008

Data de Aprovação: 30/ 11/ 2010 